\title{
High performance liquid chromatography: Tandem mass spectrometric determination of cisplatin levels in different visceral pleura layers of rats
}

\author{
HUI XIA, WEN ZHANG, YINGJIE LI and CHANGHAI YU \\ Department of Thoracic-Cardio Surgery, First Affiliated Hospital of PLA General Hospital, Beijing 100048, P.R. China
}

Received June 30, 2014; Accepted February 6, 2015

DOI: $10.3892 / \mathrm{ol} .2015 .2989$

\begin{abstract}
The aim of the present study was to investigate the concentration of cisplatin in different layers of the visceral pleura in rats, following drug administration. In this study, a sensitive and specific liquid chromatography method coupled with electrospray ionization-tandem mass spectrometry was established to investigate the disposition of cisplatin in different layers of the visceral pleura in rats. Methodological data, including specificity, linearity, accuracy, recovery, precision and lower limits of quantification, confirmed that this novel method may be used to efficiently quantify the cisplatin concentrations in visceral pleura of rats following administration of the drug. Furthermore, the results demonstrated that the desired drug concentration was not achieved in the outer or inner elastic layers of the visceral pleura following injection with cisplatin through various administration methods.
\end{abstract}

\section{Introduction}

Lung cancer has a high mortality rate, accounting for $>12 \%$ of all newly diagnosed cases of cancer with a poor prognosis, and is the leading cause of cancer-associated mortality worldwide $(1,2)$. Non-small-cell lung cancer (NSCLC) accounts for $\sim 80 \%$ of all lung cancer cases and has a five-year overall survival rate of $<15 \%(3,4)$. In addition, $\sim 40 \%$ of NSCLC patients have medically inoperable or unresectable stage III disease at the time of diagnosis (5). Malignant pleural effusion or pleural nodules are also common occurrences during NSCLC progression, particularly in adenocarcinoma, due to its location in the periphery of the lung allowing invasion into the pleural cavity $(6,7)$.

Visceral pleural invasion (VPI) is the most significant prognostic factor in lung cancer, and is associated with advanced

Correspondence to: Professor Changhai Yu, Department of Thoracic-Cardio Surgery, First Affiliated Hospital of PLA General Hospital, 51 Fucheng Road, Beijing 100048, P.R. China E-mail: yuchanghai1@hotmail.com

Key words: cisplatin, visceral pleura layer, disposition, liquid chromatography/electrospray ionization-tandem mass spectrometry tumor stages. The visceral pleura comprises two elastic layers: The outer elastic layer, which is thick and lies beneath the submesothelial layer; and the inner elastic layer, which is thinner and located close to the pulmonary parenchyma. No elastic fibers are present between the pleural surface and the outer elastic layer; therefore, the outer elastic layer is more easily recognized than the inner elastic layer $(8,9)$. Based on extensive evidence from previous reports, the International Association for the Study of Lung Cancer (IASLC) proposed the 7 th revision of the tumor-node-metastasis (TNM) staging system for NSCLC in $2009(10,11)$. According to the TNM staging system, VPI may be classified into the following stages: pl0, lung tumor with no pleural involvement beyond its elastic layer; pl1, lung tumor extending beyond the elastic layer of the visceral pleura, without being exposed on the pleural surface; and $\mathrm{pl} 2$, lung tumor that is exposed on the pleural surface, without involvement of adjacent anatomical structures $(12,13)$. Incomplete resection and the presence of nodal involvement have been consistently reported to be poor prognostic factors in cases of NSCLC with chest wall invasion (14). Additionally, the depth of chest wall invasion may affect prognosis following lung cancer resection $(14,15)$.

Previous clinical studies have demonstrated that cisplatin may be used as a primary chemotherapeutic agent for the treatment of lung cancer $(16,17)$. Certain studies have also revealed that cisplatin is able to bind to the $\mathrm{N} 7$ position of purine DNA bases, constructing cross-links between adjacent guanines. The ability of cisplatin to react with cellular DNA results in the formation of DNA adducts, accounting for its cytotoxic activity and ability to induce apoptosis $(18,19)$. However, despite its clinical use in the treatment of lung cancer, side effects and drug resistance have been reported (20). Investigating the disposition of cisplatin in the different visceral pleura layers may provide further insight into the in vivo targets of cisplatin in lung cancer therapy. A novel sensitive and specific analytical method is required to facilitate such evaluation.

Tandem mass spectrometry (MS/MS) and electrospray ionization (ESI) are novel techniques that, along with advances in mass spectrometry (MS), may markedly improve the sensitivity, selectivity and specificity of drug detection. In certain studies, liquid chromatography (LC) coupled with MS/MS was used as the primary method for identifying and quantifying the tissue distribution of parent compounds $(21,22)$. 
Compared with gas chromatography and high-performance liquid chromatography (HPLC), the LC-MS/MS method has a number of advantages, including rapid analytical run-time, minimization of the mobile phase and use of small sample volumes $(23,24)$.

The aim of the present study was to investigate the levels of cisplatin in different layers of the visceral pleura in rats, following drug administration. A previously developed LC-MS/MS method with rapid analysis and high sensitivity was validated for use in the detection of cisplatin concentration in different elastic layers of the visceral pleura in rats.

\section{Materials and methods}

Reagents. Cisplatin and apigenin were purchased from Sigma-Aldrich (St. Louis, MO, USA). All other reagents were of analytical grade or HPLC grade, and were obtained from DIMA Technology, Inc. (Richmond Hill, GA, USA).

Analytical procedures. Cisplatin was separated by HPLC using a Symmetry C18 column (50x2.1 mm; Waters Corporation, Beverly, MA, USA). The elution conditions were as follows: Solvent A, $0.1 \%$ (v/v) aqueous formic acid; solvent $\mathrm{B}$, acetonitrile (100\%); and flow rate, $0.2 \mathrm{ml} / \mathrm{min}$ with $25 \%$ solvent $\mathrm{A}$ and $75 \%$ solvent $\mathrm{B}$. A high-throughput and sensitive bioanalytical method was developed using LC/ESI-MS/MS. The interface was used to generate positive ions, $[\mathrm{M}-\mathrm{H}]^{+}$, for the estimation of the cisplatin concentration in tissues. Argon was used as the collision gas at a rate of $0.2 \mathrm{ml} / \mathrm{min}$, while nitrogen was used as the desolvation gas at a rate of $450 \mathrm{ml} / \mathrm{min}$. The electrospray capillary voltage was $3.0 \mathrm{kV}$, and the source temperature was $110^{\circ} \mathrm{C}$. For quantification of cisplatin, a previously described internal standard (IS) method $(25,26)$, using the peak area ratio, was used in combination with multiple reaction monitoring (MRM) of the deprotonation precursor ion and the associated product ion for cisplatin. Collision-induced dissociation was achieved using argon. The Masslynx Analyst software (version 4.1; Waters Corporation) was selected for data acquisition.

Preparation of calibration curves. Stock solutions of cisplatin and IS $(1.0 \mathrm{mg} / \mathrm{ml})$ were prepared by dissolving various amounts of the substances in methanol. Tissue homogenates of the rat visceral pleura layer, including cisplatin $(0.5,1.0$, $10,20,50$ and $100 \mathrm{ng} / \mathrm{ml})$ and IS working solution $(50 \mathrm{ng} / \mathrm{ml}$ apigenin solution dissolved in methanol) were combined and extracted using acetidin (Tianjin Kermel Chemical Reagent Co., Ltd., Tianjin, China) (25,27). Following vigorous vortexing for $1 \mathrm{~min}$ and centrifugation at $3,000 \mathrm{xg}$ for $10 \mathrm{~min}$, the supernatant was collected and evaporated to dryness under nitrogen at $55^{\circ} \mathrm{C}$. The residue was subsequently dissolved in methanol $(100 \mu \mathrm{l})$ and reconstituted prior to LC-MS/MS analysis.

Recovery, precision and accuracy. The peak area ratio of cisplatin to the IS was calculated, and the extract recovery was measured at concentrations of $1.0,5.0$ and $50.0 \mathrm{ng} / \mathrm{ml}$. Next, the accuracy [expressed as the percentage of relative error (RE)] was determined by calculating the values of quality control samples with various concentrations of cisplatin. The inter-day accuracy and precision [expressed as the percentage of relative standard deviation (RSD)] were determined following daily analysis of the quality control samples over a three-day period. The method was assessed for linearity, recovery, accuracy and precision.

Sampling and sample preparation. Sprague-Dawley rats ( $\mathrm{n}=66$, age, 70-110 days; weight, 270-320 g) were obtained from the Experimental Animal Center of the PLA General Hospital (Beijing, China). The rats were fasted overnight with free access to water prior to the day of the experiment. The experiments were approved by the Animal Ethics Committee of the PLA General Hospital (Beijing, China). All the measurements were performed in a coded and blinded manner.

The rats were anesthetized with diethyl ether at $0.17,0.33$, $0.5,1,2,4,8,12,16,24$ and $36 \mathrm{~h}$ after administration of cisplatin, in order to collect blood samples from the abdominal aorta and tissue samples from different visceral pleura layers ( $n=6$ in each group). Tissue samples were weighed prior to homogenization. Based on the aforementioned sample preparation methods, the tissue samples with cisplatin were analyzed using LC-MS/MS.

Statistical analysis. Viability parameters were compared using the Student's $t$-test for unpaired observations. $\mathrm{P}<0.05$ was considered to indicate a statistically significant difference. All the pharmacokinetic parameters were analyzed using the 3P97 pharmacokinetics software version 97 (Chinese Academy of Sciences, Beijing, China).

\section{Results and Discussion}

In the current experiments, the mass signals of cisplatin were stronger in the positive ESI mode when compared with the negative mode; therefore, the negative mode was used for optimization of the mass. Following injection of the standard solutions into a mass spectrometer, parent ions of cisplatin and IS were obtained at a mass-to-charge ratio $(\mathrm{m} / \mathrm{z})$ of 302.7 and 268.9, respectively. After these parent ions collided with argon in quadrupole (Q)2 of the MS/MS system, the corresponding product ion with the most sensitive quantification conditions was scanned in Q3. Therefore, an MRM transition from $\mathrm{m} / \mathrm{z} 302.7$ to 253.4 for cisplatin and from $\mathrm{m} / \mathrm{z} 268.9$ to 150.6 for apigenin (internal standard) were used for quantification with the optimal mass condition. A cone voltage of $30 \mathrm{~V}$ and collision energy of $25 \mathrm{eV}$ were used for cisplatin, whereas a cone voltage of $45 \mathrm{~V}$ and collision energy of $20 \mathrm{eV}$ were used for apigenin.

With regard to the chromatographic conditions, the analytical column and mobile phase were optimized following several trials, in order to obtain the shortest run-time, optimum separation, highest sensitivity and symmetric peak shapes for cisplatin and apigenin. The retention times for cisplatin and apigenin were 1.18 and $2.25 \mathrm{~min}$, respectively.

Standard curves were developed for the quantification of cisplatin following the analysis of tissue samples with different concentrations of cisplatin $(0.5,1,10,20,50$ and $100 \mathrm{ng} / \mathrm{ml}$ ). After calculating the peak area ratio of cisplatin (y-axis) or IS against the analyte concentration (x-axis), linear regression analysis of cisplatin was conducted. Using the LC/ESI-MS/MS method, the standard curves demonstrated a 
Table I. Pharmacokinetics of cisplatin following injection in visceral pleura.

\begin{tabular}{lccccc}
\hline Disposition & $\mathrm{K}, \mathrm{h}^{-1}$ & $\mathrm{~T}_{1 / 2 \mathrm{Ke}}, \mathrm{h}$ & $\mathrm{T}_{\text {peak }}, \mathrm{h}$ & $\mathrm{C}_{\max }, \mathrm{ng} / \mathrm{ml}$ & $\mathrm{AUC}, \mathrm{ng} \times \mathrm{h} / \mathrm{ml}$ \\
\hline Outer & $0.2 \pm 0.1$ & $3.3 \pm 0.1$ & 1.0 & $8.3 \pm 0.4$ & $71.3 \pm 6.7$ \\
Inner & $0.1 \pm 0.1$ & $3.9 \pm 0.1$ & 2.0 & $10.1 \pm 0.7$ & $89.6 \pm 5.3$ \\
\hline
\end{tabular}

Data are presented as the mean \pm standard deviation $(n=6)$. Outer, outer elastic layer; inner, inner elastic layer; AUC, area under the curve; K, elimination rate; $\mathrm{T}_{1 / 2 \mathrm{Ke}}$, elimination half-life; $\mathrm{T}_{\text {peak }}$, time taken to reach $\mathrm{C}_{\max } ; \mathrm{C}_{\max }$, maximum plasma concentration of drug after administration.

Table II. Pharmacokinetics of cisplatin following caudal vein injection.

\begin{tabular}{lccccc}
\hline Disposition & $\mathrm{K}, \mathrm{h}^{-1}$ & $\mathrm{~T}_{1 / 2 \mathrm{Ke}}, \mathrm{h}$ & $\mathrm{T}_{\text {peak }}, \mathrm{h}$ & $\mathrm{C}_{\max }, \mathrm{ng} / \mathrm{ml}$ & $\mathrm{AUC}, \mathrm{ng} \mathrm{x} \mathrm{h} / \mathrm{ml}$ \\
\hline Plasma & $0.5 \pm 0.1$ & $1.2 \pm 0.1$ & 0.17 & $43.2 \pm 3.7$ & $312.5 \pm 18.3$ \\
Outer & $0.3 \pm 0.1$ & $3.7 \pm 0.2$ & 0.5 & $5.6 \pm 0.3$ & $46.4 \pm 4.7$ \\
Inner & $0.2 \pm 0.1$ & $4.3 \pm 0.1$ & 1.0 & $6.1 \pm 0.6$ & $52.1 \pm 3.2$ \\
\hline
\end{tabular}

Data are presented as the mean \pm standard deviation $(n=6)$. Outer, outer elastic layer; inner, inner elastic layer; AUC, area under the curve; K, elimination rate; $\mathrm{T}_{1 / 2 \mathrm{Ke}}$, elimination half-life; $\mathrm{T}_{\text {peak }}$, time taken to reach $\mathrm{C}_{\max } ; \mathrm{C}_{\max }$, maximum plasma concentration of drug after administration.

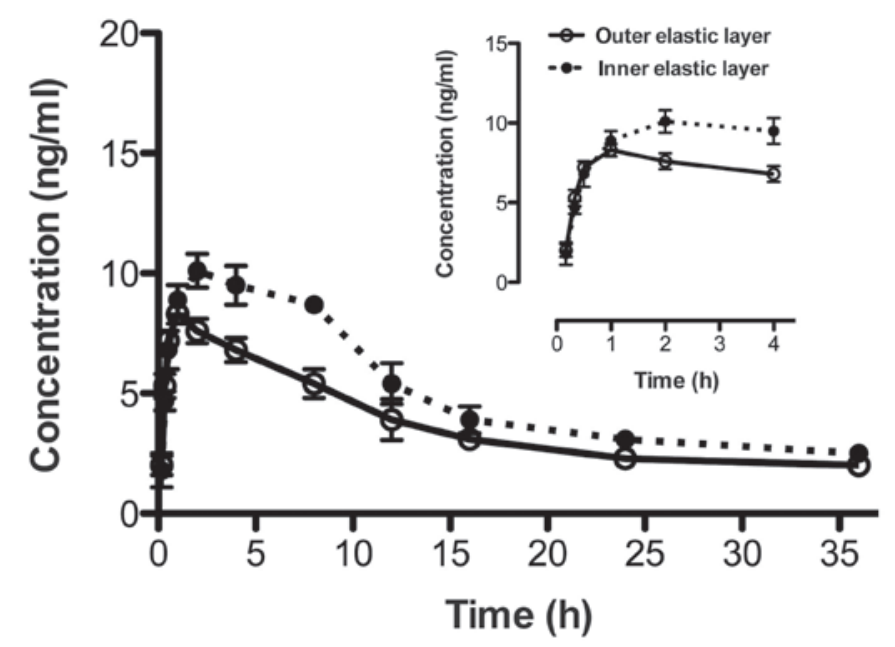

Figure 1. Time course of cisplatin concentrations following injection into the visceral pleura layers. The concentration levels of cisplatin in the outer and inner elastic layers were measured following injection of cisplatin into the visceral pleura. Data points are presented as the mean \pm standard deviation ( $\mathrm{n}=6$ ).
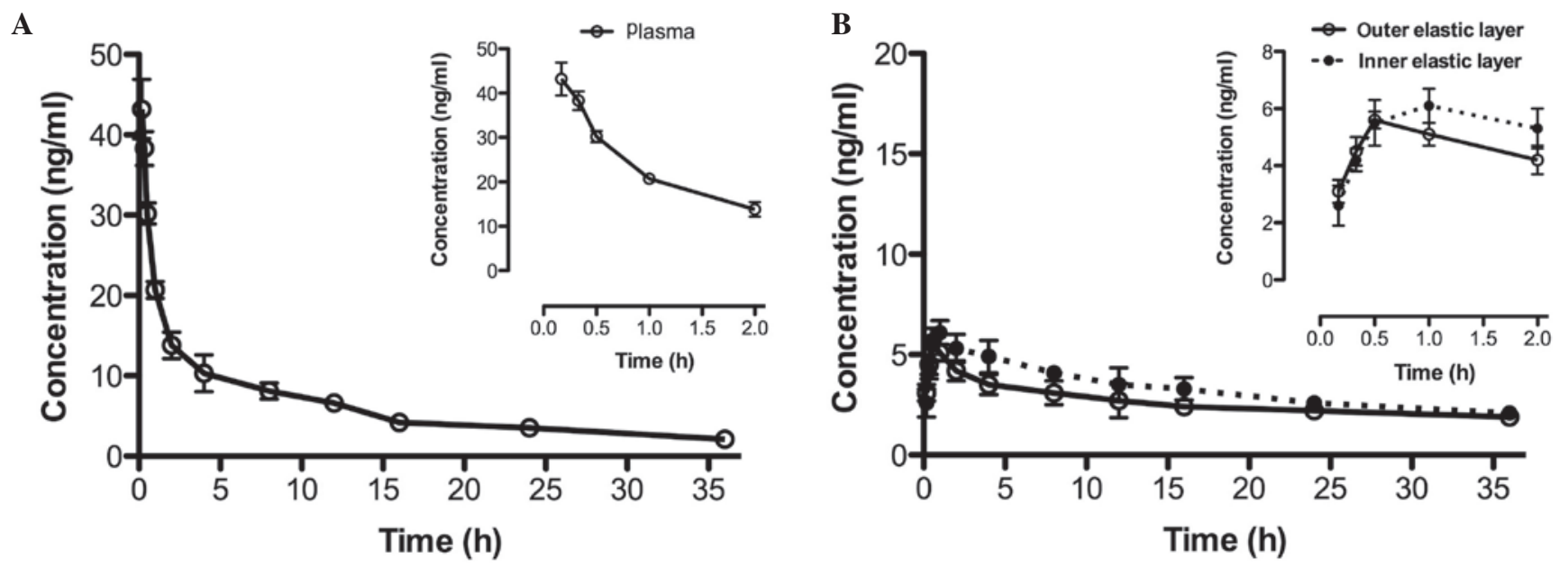

Figure 2. Time course of cisplatin concentrations following caudal vein injection. (A) Rat plasma concentrations. (B) Concentration of cisplatin in outer and inner elastic layers following caudal vein injection of cisplatin. Data points are presented as the mean \pm standard deviation $(n=6)$. 
good linear response $\left(r^{2}>0.9986 ; n=6\right)$ for tissue samples with concentrations between 0.5 and $100.0 \mathrm{ng} / \mathrm{ml}$, while the regression equation was $\mathrm{y}=0.927 \mathrm{x}-0.025$.

The lower limit of quantification (LLOQ) represented the lowest concentration that can be confirmed with sufficient accuracy $(\mathrm{RE} \leq 20 \%)$ and precision $(\mathrm{RSD} \leq 20 \%)$. In order to obtain the lower detection limit in the current study, the biological samples were treated with ethyl acetate to achieve efficient cleanup and reduce the matrix effects, which influence the ionization and detection of cisplatin. The LLOQ was determined to be $0.1 \mathrm{ng} / \mathrm{ml}$ at a signal-to-noise ratio of $>10$, with $\mathrm{RE}<13.5 \%$ and $\mathrm{RSD}<11.3 \%(\mathrm{n}=6)$. The chromatograms of cisplatin and apigenin, without endogenous interfering peaks, exhibited no clear matrix effects in the rat tissue samples.

In the present study, a liquid-liquid extraction method, which is able to reduce matrix effects, was used to prevent contamination or interference in the mass spectra of the tissue samples, as described in previous reports (28). This extraction procedure may improve the peak shape, as well as the assay sensitivity, precision or accuracy, by removing protein precipitates and minimizing ion suppression. In addition, intra- and inter-day precision was found to vary by $\leq 12.7 \%$. Furthermore, control samples treated with cisplatin were analyzed as described. Low, middle and high concentrations were selected to evaluate the recovery of cisplatin and apigenin during extraction. Recovery was determined to be $85.4 \pm 2.7 \%, 87.3 \pm 1.6 \%$ and $89.5 \pm 2.3 \%$ $(n=6)$ for the low, middle and high concentrations, respectively, which demonstrates the robust efficiency of this method.

In addition, the aforementioned LC-MS/MS method was validated and used to quantify the distribution of cisplatin in the different visceral pleura layers following administration of cisplatin to rats. When cisplatin $(5 \mathrm{mg} / \mathrm{kg})$ was injected into the visceral pleura layers of the rats, the maximum plasma concentration of drug after administration $\left(\mathrm{C}_{\max }\right)$ values of cisplatin were $8.3 \pm 0.4 \mathrm{ng} / \mathrm{ml}$ (at $1.0 \mathrm{~h}$ post-injection) and $10.1 \pm 0.7 \mathrm{ng} / \mathrm{ml}$ (at $2.0 \mathrm{~h}$ post-injection; $\mathrm{n}=6$ ) in the outer and inner elastic layers, respectively. The changes in cisplatin disposition in the different visceral pleura layer are shown in Fig. 1, while the pharmacokinetic parameters are listed in Table I.

Following injection of cisplatin $(5 \mathrm{mg} / \mathrm{kg})$ through the caudal vein,the $\mathrm{C}_{\text {max }}$ value of cisplatinwas $43.2 \pm 3.7 \mathrm{ng} / \mathrm{mlintheratplasma}$ (Fig. 2A) and was reached at $0.17 \mathrm{~h}$ post-injection. In addition, the area under the curve was determined to be $312.5 \pm 18.3 \mathrm{ng} \mathrm{x} \mathrm{h/ml}$. In the outer and inner elastic layers, the $C_{\max }$ values were $5.6 \pm 0.3 \mathrm{ng} / \mathrm{ml}$ and $6.1 \pm 0.6 \mathrm{ng} / \mathrm{ml}(\mathrm{n}=6)$, at $0.5 \mathrm{~h}$ and $1.0 \mathrm{~h}$, respectively (Fig. 2B; Table II).

Furthermore, after the injection of cisplatin through the caudal vein, the plasma concentration rapidly reached $\mathrm{C}_{\max }$; however, in the visceral pleura layer, no sufficient therapeutic concentration of cisplatin was obtained in the outer or inner elastic layers. For the visceral pleural invasion of lung cancer, chest wall invasion has been found to occur in the majority of stages $(29,30)$. The results of the current study indicate that standard cisplatin chemotherapy for the treatment of lung cancer with VPI may not produce the desired therapeutic effects due to insufficient drug concentration in the target region. Therefore, chemotherapy only may not be a viable treatment strategy for these patients. In addition, injection of cisplatin into the visceral pleura layers demonstrated that a sufficient therapeutic concentration of cisplatin was not reached in the outer or inner elastic layers.
Based on the results of the present study, it is hypothesized that surgical intervention in combination with chemotherapy for lung cancer with VPI may be a more effective treatment strategy compared with chemotherapy only. Clinical research must be performed to acquire additional data and further understanding to establish an optimal treatment for this disease.

\section{References}

1. Hinojosa de la Garza OR, Sanín LH, Montero Cabrera ME, et al: Lung cancer mortality and radon concentration in a chronically exposed neighborhood in Chihuahua, Mexico: a geospatial analysis. ScientificWorldJournal 2014: 935380, 2014.

2. Torre LA, Bray F, Siegel RL, et al: Global cancer statistics, 2012. CA Cancer J Clin: Feb 4, 2015 (Epub ahead of print).

3. Fidias P and Novello S: Strategies for prolonged therapy in patients with advanced non-small-cell lung cancer. J Clin Oncol 28: 5116-5123, 2010.

4. Cohen MH, Cortazar P, Justice R and Pazdur R: Approval summary: Pemetrexed maintenance therapy of advanced/metastatic nonsquamous, non-small cell lung cancer (NSCLC). Oncologist 15: 1352-1358, 2010.

5. Bareschino MA, Schettino C, Rossi A, et al: Treatment of advanced non small cell lung cancer. J Thorac Dis 3: 122-133, 2011.

6. Leighl NB: Treatment paradigms for patients with metastatic non-small-cell lung cancer: First-, second-, and third-line. Curr Oncol 19: S52-S58, 2012.

7. Sangha R, Price J and Butts CA: Adjuvant therapy in non-small cell lung cancer: Current and future directions. Oncologist 15: $862-872,2010$

8. Ost D, Goldberg J, Rolnitzky L and Rom WN: Survival after surgery in stage IA and IB non-small cell lung cancer. Am J Respir Crit Care Med 177: 516-523, 2008.

9. Riquet M, Arame A and Mordant P: Visceral pleural invasion: a prognostic factor beginning with small size and increasing with the progression of lung cancer. Ann Thorac Surg 97: 383, 2014.

10. van Meerbeeck JP and Janssens A: The seventh tumour-nodemetastasis staging system for lung cancer: Sequel or prequel? Europ J Cancer Suppl 11: 150-158, 2013.

11. Detterbeck FC, Boffa DJ and Tanoue LT: The new lung cancer staging system. Chest 136: 260-271, 2009

12. Cho S, Park TI, Lee EB and Son SA: Poor Prognostic Factors in Surgically Resected Stage I Non-small Cell Lung Cancer: Histopathologic and Immunohistochemical Analysis. Korean J Thorac Cardiovasc Surg 45: 101-109, 2012.

13. Park SY, Lee JG, Kim J, et al: Efficacy of platinum-based adjuvant chemotherapy in T2aN0 stage IB non-small cell lung cancer. J Cardiothorac Surg 8: 151, 2013.

14. Kawase A, Yoshida J, Miyaoka E, et al: Visceral pleural invasion classification in non-small-cell lung cancer in the 7th edition of the tumor, node, metastasis classification for lung cancer: validation analysis based on a large-scale nationwide database. J Thorac Oncol 8: 606-611, 2013.

15. Hattori A, Suzuki K, Matsunaga T, et al: Visceral pleural invasion is not a significant prognostic factor in patients with a part-solid lung cancer. Ann Thorac Surg 98: 433-438, 2014.

16. O'Byrne KJ, Barr MP and Gray SG: The role of epigenetics in resistance to Cisplatin chemotherapy in lung cancer. Cancers Basel 3: 1426-1453, 2011.

17. Wangpaichitr $\mathrm{M}$, Wu C, You M,et al: N',N'-Dimethyl-N',N'bis(phenylcarbonothioyl) Propanedihydrazide (Elesclomol) Selectively Kills Cisplatin Resistant Lung Cancer Cells through Reactive Oxygen Species (ROS). Cancers Basel 1: 23-38, 2009.

18. Wu XX and Kakehi Y: Enhancement of lexatumumab-induced apoptosis in human solid cancer cells by Cisplatin in caspase-dependent manner. Clin Cancer Res 15: 2039-2047, 2009.

19. Sanborn RE: Cisplatin versus carboplatin in NSCLC: Is there one "best" answer. Curr Treat Options Oncol 9: 326-342, 2008.

20. Chang A: Chemotherapy, chemoresistance and the changing treatment landscape for NSCLC. Lung Cancer 71: 3-10, 2011.

21. Mudiam MK, Chauhan A, Jain R, et al: Molecularly imprinted polymer coupled with dispersive liquid-liquid microextraction and injector port silylation: a novel approach for the determination of 3-phenoxybenzoic acid in complex biological samples using gas chromatography-tandem mass spectrometry. J Chromatogr B Analyt Technol Biomed Life Sci 945-946: 23-30, 2014. 
22. Hoofnagle AN and Roth MY: Clinical review: Improving the measurement of serum thyroglobulin with mass spectrometry. J Clin Endocrinol Metab 98: 1343-1352, 2013.

23. Gosetti F, Mazzucco E, Gennaro MC and Marengo E: Ultra high performance liquid chromatography tandem mass spectrometry determination and profiling of prohibited steroids in human biological matrices. A review. J Chromatogr B Analyt Technol Biomed Life Sci 927: 22-36, 2013.

24. Gouveia MJ, Brindley PJ, Santos LL, et al: Mass spectrometry techniques in the survey of steroid metabolites as potential disease biomarkers: A review. Metabolism 62: 1206-1217, 2013.

25. Bielawski J, Szulc ZM, Hannun YA and Bielawska A: Simultaneous quantitative analysis of bioactive sphingolipids by high-performance liquid chromatography-tandem mass spectrometry. Methods 39: 82-91, 2006.

26. Liu X, Teng Z, Zhang Y, et al: High performance liquid chromatography-tandem mass spectrometric determination of resveratrol and its metabolites in rat tissues. Anal Lett 43: 557-569, 2010.
27. Chow TW, Szeitz A, Rurak DW and Riggs KW: A validated enantioselective assay for the simultaneous quantitation of (R)-, (S)-fluoxetine and (R)-, (S)-norfluoxetine in ovine plasma using liquid chromatography with tandem mass spectrometry (LC/MS/MS). J Chromatogr B Analyt Technol Biomed Life Sci 879: 349-358, 2011.

28. Nordberg H, Jerndal G and Thompson RA: Direct injection of lipophilic compounds in the organic phase from liquid-liquid extracted plasma samples onto a reversed-phase column. Bioanalysis 3: 1963-1973, 2011.

29. Haam SJ, Park IK, Paik HC, et al: T-stage of non-small cell lung cancer directly invading an adjacent lobe. Eur J Cardiothorac Surg 42: 807-810, 2012

30. Torii I, Hashimoto M, Terada T, et al: Well-differentiated papillary mesothelioma with invasion to the chest wall. Lung Cancer 67: 244-247, 2010. 